\title{
Synthesis of Bioactive Fluoropyrrolidines via Copper(I)-Catalyzed Asymmetric 1,3-Dipolar Cycloaddition of Azomethine Ylides
}

\section{Xiao Xu}

Huazhong Agricultural University

\section{Longzhu Bao}

Huazhong Agricultural University

\section{Lu Ran}

Yunnan Food Safety Research Institute, Kunming University of Science and Technology

\section{Zhenyan Yang}

Huazhong Agricultural University

\section{Dingce Yan}

Huazhong University of Science and Technology

\section{Chun-Jiang Wang}

Wuhan University

Huailong Teng ( $\nabla$ thlong@mail.hzau.edu.cn )

Huazhong Agricultural University https://orcid.org/0000-0001-7544-2856

\section{Article}

Keywords: organic chemsistry, catalysis, chiral pyrrolidinyl, organic molecules

Posted Date: July 12th, 2021

DOl: https://doi.org/10.21203/rs.3.rs-668921/v1

License: (9) This work is licensed under a Creative Commons Attribution 4.0 International License. Read Full License

Version of Record: A version of this preprint was published at Chemical Science on January 1st, 2021. See the published version at https://doi.org/10.1039/D1SC04595D. 


\title{
Synthesis of Bioactive Fluoropyrrolidines via Copper(I)-Catalyzed Asymmetric 1,3-Dipolar Cycloaddition of Azomethine Ylides
}

\author{
Xiao Xu, ${ }^{\dagger 1}$ Longzhu Bao, ${ }^{+1}$ Lu Ran, ${ }^{1}$ Zhenyan Yang, ${ }^{1}$ Dingce Yan, ${ }^{3}$ Chun-Jiang Wang, ${ }^{* 2}$ and Huailong Teng $* 1$
}

Chiral pyrrolidinyl units are important building blocks in biologically active natural products and drugs, thereupon, searching approaches for the synthesis of diverse structured pyrrolidine derivatives is of great importance. Meanwhile, owing to the special physicochemical properties of fluorine atoms, the introduction of fluorine containing groups into small molecules often change their activities to a great extent. Herein, we reported an efficient route to chiral 3,3-difluoro- and 3,3,4-trifluoropyrrodinyl derivatives by $\mathrm{Cu}(\mathrm{I})$-catalyzed enantioselective 1,3-dipolar cycloaddition of azomethine ylides with less active 1,1-difluoro- and 1,1,2trifluoroalkenes. A series of new fluorinated pyrrolidines have been prepared in high yields (up to $96 \%$ ) and excellent stereoselectivities (up to $>20: 1 \mathrm{dr}$ and $97 \%$ ee), and these unique structural blocks could be readily introduced into some natural compounds and pharmaceuticals. Additionally, antifungal activity investigation against four common plant funguses showed that some products possess general and high biological activities (up to $93 \%$ inhibition rate), the comparison with the antifungal activities of corresponding non-fluorinated compounds (low to $13 \%$ inhibition rate) revealed that the fluorine atoms at pyrrolidinyl rings play a crucial role in the antifungal activity, which prove the special properties of fluorine atoms in organic molecules.

$\mathrm{F}$ luoro-organic chemistry is one of the most fiery-hot areas in modern chemistry, and has currently become crucial in the evolution of many transdisciplinary research fields. ${ }^{1-4}$ The determinant impact of fluorine is undoubtedly associated with pharmaceutical and agrochemical industry. Due to the special properties, introduction of fluorine containing groups into compounds often affect their biological activity a lot (Figure 1) and thus has always been regarded as a powerful tactics in agrochemicals and pharmaceuticals creation. ${ }^{5-14}$ Accounting to recent survey, about half of newly developed pesticides and $35 \%$ of new drug candidates in phase II-III clinical trials contain distinct kinds of fluorine-substituted moieties. ${ }^{15-17}$ During the past decades, the remarkable success and huge requirement of fluorine compounds in various fields have provided infinite vitality for organic chemists to explore methods for the construction of fluorinated molecules. ${ }^{18-22}$

In the other hand, enantioenriched pyrrolidinyl groups, which are important building blocks in many biologically active natural alkaloids and pharmaceuticals, has attracted much attention recent years. ${ }^{23-28}$ The transition-metal-catalyzed asymmetric 1,3-dipolar cycloaddition of azomethine ylides with electron deficient alkenes represent one of the most powerful routes for the stereo-controlled synthesis of these molecules. ${ }^{29-34}$ Taking the crucial property of fluorine atoms in consideration, engrafting fluorine atoms into heterocycle rings in chiral pyrrolidine derivatives would change their bioactivities to a great extent. In principle, the asymmetric 1,3dipolar cycloaddition of azomethine ylides with fluoroalkenes could lead to multiple fluorinated pyrrolidines, however, rare research work focused on the construction and bioactivity evaluation of such molecules have been reported to date.

Most recently, gem-difluoroalkenes, which could be easily prepared by witting reaction of difluoro-phosphorus ylide with various aldehydes and ketones, ${ }^{35}$ gain a lot of interest. Owing to their multiple reactivities, these reactants could participated in various organic transformations to access prosperous substituted fluorocompounds. The transition metal or photocatalytic addition- elimination of nucleophiles or free radicals to gem-difluoroalkenes could lead to monofluoro-alkenes (Scheme 1a). ${ }^{36-44}$ While nucleophiles or free radicals could also add directly to gemdifluoroalkenes without fluorine elimination, giving difluoromotifs (Scheme 1b). ${ }^{45-47}$ Moreover, novel strategies have been reported by taking advantage of gem-difluoroalkenes as reliable trifluoromethyl $\left(\mathrm{CF}_{3}\right)$ precursors through $\mathrm{F}^{+} / \mathrm{F}^{-}$addition initialized cascade reactions (Scheme 1c). ${ }^{47-52}$ In 2020, Zhang and coworkers realized an asymmetric fluoroarylation of gem-difluoroalkenes by using their newly developed TY-Phos, which is heretofore the only asymmetric transformation of gem-difluoroalkenes. ${ }^{53}$ Despite of the comprehensive application of gem-difluoroalkenes in the synthesis of structurally diverse fluoro-compounds, asymmetric cycloaddition of these substrates still remain blank.

In this work, an enantioselective 1,3-dipolar cycloaddition of azomethine ylides with gem-1,1-difluoroalkenes and 1,1,2trifluoroalkenes was achieved by a $\mathrm{Cu}(\mathrm{I}) / \mathrm{DTBM}-\mathrm{Segphos}$ catalyst. To achieve this transformation, two challenges shown in Scheme 1d must be overcame. First, the high activation barrier is a big

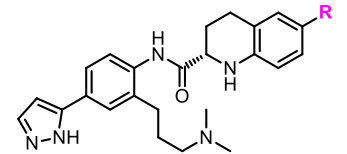

Inhibitors for Rho kinase Analogue I: $(R=H): I C_{50}=590$; Analogue II: $(R=F): I C_{50}=7$.

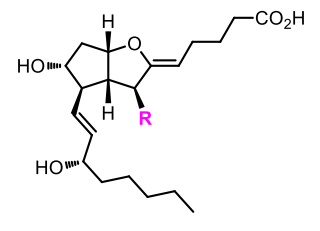

Half life in vivo $\left(t_{1 / 2}, \mathrm{pH}=7.4\right)$ PGI2 $(R=H): 10$ mins;

7-F-PGI2 $(R=F)$ : > 30 days

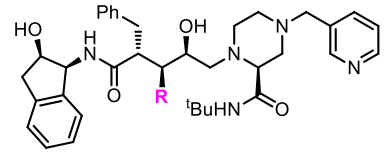

Inhibitors for HIV-1 protease C17-epi-Indinavir $(\mathrm{R}=\mathrm{H}): K_{\mathrm{i}}=160 \mathrm{nM}$;

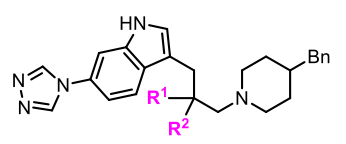

Affinities at $5-\mathrm{HT}_{1 \mathrm{D}}$ receptor Analogue $\mathrm{I}: \mathrm{R}^{1}=\mathrm{R}^{2}=\mathrm{H}: \mathrm{IC}_{50}=0.3$; Analogue II: $\mathrm{R}^{1}=\mathrm{H}, \mathrm{R}^{2}=\mathrm{F}: \mathrm{IC}_{50}=0.9$ Analogue III: $\mathrm{R}^{1}=\mathrm{R}^{2}=\mathrm{F}: \mathrm{IC}_{50}=78$. Fluorinated analogue $(R=F): K_{i}=20 n M$

Figure 1 | Fluorine factors on biological activity. 
Previous work

(a) Synthesis of monofluoro-alkenes by nucleophilic addition-elimination reactions

$$
\mathrm{Ar}_{\mathrm{F}}^{\mathrm{F}}+\mathrm{Nu}^{-} \text {or } \mathrm{R}^{\bullet} \stackrel{\mathrm{Cu}, \mathrm{Pd}, \mathrm{Rh}, \mathrm{PS}^{\star}+h v \ldots}{\longrightarrow} \mathrm{Ar} \overbrace{\mathrm{F}}^{\mathrm{Nu}(\mathrm{R})}
$$

(b) Synthesis of difluoro-compounds via nucleophilic addition reactions

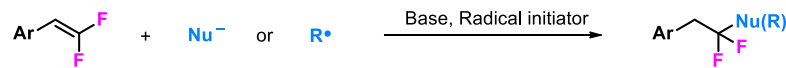

(c) Synthesis of trifluoro-compounds through F-addition induced cascade reactions

$$
\overbrace{\mathrm{F}}^{\mathrm{F}}+\mathrm{F}^{-} / \mathrm{E}^{+} \text {or } \mathrm{F}^{+} / \mathrm{Nu}^{-} \stackrel{\mathrm{Ag}, \mathrm{Cu}, \mathrm{Pd}, \mathrm{PS}^{*}+h v \ldots}{\longrightarrow}
$$

This work:

(d) Synthesis of bioactive fluoropyrrolidines by asymmetric [3+2] cycloaddition

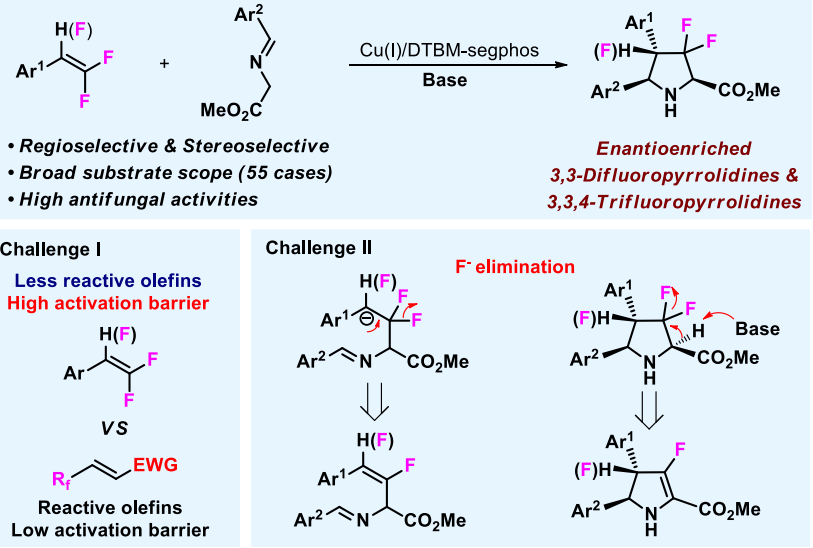

Scheme 1 | Synthesis of fluorochemicals from difluoroalkenes.

difficulty, as known, 1,3-dipolar cycloaddition of azomethine yilde is generally limited to highly activated dipolarophiles bearing strong electron withdrawing substituents, ${ }^{29-34}$ only a few cases are associated with less reactive olefins. Martín and coworkers reported a $\operatorname{Ag}(\mathrm{I})$-catalyzed asymmetric 1,3-dipolar cycloaddtion of azomethine ylide with $\mathrm{C}_{60},{ }^{54}$ while the reaction with less activated alkenyl arenes was achieved by Carretero et. al. ${ }^{55-57}$ In spite of these rare examples, the reaction of inactive alkenes remains a great challenge in some sense. Besides, as shown scheme $1 \mathrm{a}$ and $1 \mathrm{~d}$, the elimination of fluorine atoms in intermediates and products is another big problem for these reactions. ${ }^{58}$

\section{Results and discussion}

Reaction condition optimizations. In the initial studies, imino ester 1a was chose as azomethine ylide procusor and 4-Cl-gemdifluoroalkene $\mathbf{2 a}$ as dipolarphile. In the presence of $\mathrm{Cu}\left(\mathrm{CH}_{3} \mathrm{CN}\right)_{4} \mathrm{PF}_{6} /(S)$-BINAP complex $(5 \mathrm{~mol} \%)$ and $\mathrm{KO}^{t} \mathrm{Bu}(20$ $\mathrm{mol} \%$ ) in toluene, the reaction did not happen at room temperature at all (Table 1, entry 1 ), when the reaction temperature raised to 60 ${ }^{\circ} \mathrm{C}$, the desired product $3 \mathbf{a}$ was obtained in only $18 \%$ yield after 48 $\mathrm{h}$ (Table 1, entry 2 ), these results revealed that the energy barrier of this transformation is extremely high. As known, high temperature often cause side reactions and poor stereoselectivity, however, when the reaction was carried out at $80^{\circ} \mathrm{C}$ for $48 \mathrm{~h}, \mathbf{3 a}$ was obtained in $60 \%$ yield with $>20: 1 \mathrm{dr}$ and $60 \%$ ee (Table 1 , entry 3 ). Encouraged by this result, we next texted other chiral diphosphine ligands, $(S)$-Segphos $\mathbf{L} 2$ gave similar catalytic reactivity with $(S)$ BINAP $(61 \%$ yield) but with poorer enantioselectivity $(28 \%$ ee) (Table 1, entry 4). To our delight, (S)-DTBM-segphos L3 performed very well in this reaction, giving desired product $\mathbf{3} \mathbf{a}$ in $91 \%$ yield together with $>20: 1 \mathrm{dr}$ and $95 \%$ ee (Table 1 , entry 5), As shown in Table 1, Lewis acids play an important role in this reaction, when anion was changed to $\mathrm{BF}_{4}^{-}$, yield decreased to $57 \%$ although stereoselectivies maintained at the same level (>20:1 dr
Table 1 | Investigation of optimal reaction conditions. ${ }^{a}$

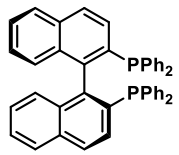

(S)-BINAP L1

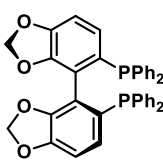

(S)-Segphos L2

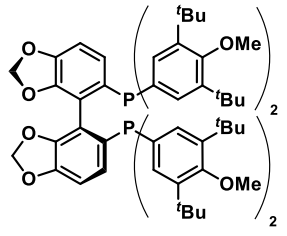

(S)-DTBM-Segphos L3

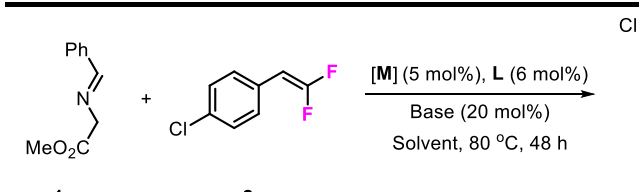

\begin{tabular}{|c|c|c|c|c|c|c|}
\hline Entry & {$[\mathbf{M}]^{\mathrm{c}}$} & Ligand & Solvent & Base & $\begin{array}{l}\text { Yield } \\
(\%)^{d}\end{array}$ & $\begin{array}{c}\mathrm{Ee} \\
(\%)^{\mathrm{e}}\end{array}$ \\
\hline 1 & $\mathrm{CuPF}_{6}$ & L1 & Toluene & $\mathrm{KO}^{t} \mathrm{Bu}$ & trace & $-^{f}$ \\
\hline 2 & $\mathrm{CuPF}_{6}$ & L1 & Toluene & $\mathrm{KO}^{t} \mathrm{Bu}$ & 18 & $-g$ \\
\hline 3 & $\mathrm{CuPF}_{6}$ & L1 & Toluene & $\mathrm{KO}^{t} \mathrm{Bu}$ & 60 & 60 \\
\hline 4 & $\mathrm{CuPF}_{6}$ & L2 & Toluene & $\mathrm{KO}^{t} \mathrm{Bu}$ & 61 & 28 \\
\hline 5 & $\mathrm{CuPF}_{6}$ & L3 & Toluene & $\mathbf{K O}^{t} \mathbf{B u}$ & 91 & 95 \\
\hline 6 & $\mathrm{CuBF}_{4}$ & L3 & Toluene & $\mathrm{KO}^{t} \mathrm{Bu}$ & 57 & 92 \\
\hline 7 & $\mathrm{CuOAc}$ & L3 & Toluene & $\mathrm{KO}^{t} \mathrm{Bu}$ & trace & - \\
\hline 8 & $\mathrm{Cu}(\mathrm{OAc})_{2}$ & L3 & Toluene & $\mathrm{KO}^{t} \mathrm{Bu}$ & trace & - \\
\hline 9 & $\mathrm{AgOAc}$ & L3 & Toluene & $\mathrm{KO}^{t} \mathrm{Bu}$ & 85 & 77 \\
\hline 10 & $\mathrm{CuPF}_{6}$ & L3 & THF & $\mathrm{KO}^{t} \mathrm{Bu}$ & 81 & 95 \\
\hline 11 & $\mathrm{CuPF}_{6}$ & L3 & $\mathrm{AcOEt}$ & $\mathrm{KO}^{t} \mathrm{Bu}$ & 61 & 94 \\
\hline 12 & $\mathrm{CuPF}_{6}$ & L3 & $\begin{array}{c}1,4- \\
\text { Dioxane }\end{array}$ & $\mathrm{KO}^{t} \mathrm{Bu}$ & 48 & 91 \\
\hline 13 & $\mathrm{CuPF}_{6}$ & L3 & Toluene & $\mathrm{K}_{2} \mathrm{CO}_{3}$ & 42 & 95 \\
\hline 14 & $\mathrm{CuPF}_{6}$ & L3 & Toluene & DIPEA & 90 & 95 \\
\hline
\end{tabular}

CI

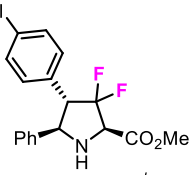

${ }^{a}$ All reactions were carried out with $0.40 \mathrm{mmol}$ of $1 \mathrm{a}$ and $0.20 \mathrm{mmol}$ of $2 \mathbf{a}$ in 2 mL solvent. ${ }^{b}$ Dr was determined by crude ${ }^{1} \mathrm{H} \mathrm{NMR} .{ }^{c} \mathrm{CuPF}_{6}=\mathrm{Cu}\left(\mathrm{CH}_{3} \mathrm{CN}\right)_{4} \mathrm{PF}_{6}$, $\mathrm{CuBF}_{4}=\mathrm{Cu}\left(\mathrm{CH}_{3} \mathrm{CN}\right)_{4} \mathrm{BF}_{4} \cdot{ }^{d}$ Isolated yield. e Ee was determined by chiral HPLC anaylsis. ${ }^{f}$ The reaction was carried out at $25{ }^{\circ} \mathrm{C}$ for $48 \mathrm{~h} .{ }^{g}$ The reaction was carried out at $60{ }^{\circ} \mathrm{C}$ for $48 \mathrm{~h}$.

and $92 \%$ ee) (Table 1 , entry 6). Neither $\mathrm{CuOAc}$ nor $\mathrm{Cu}(\mathrm{OAc})_{2}$ could make this reaction happen (Table 1, entries 7 and 8). Other metal salt such as AgOAc also worked in this transformation, however, providing the corresponding product $\mathbf{3 a}$ with moderate enantioselectivity (Table 1, entry 9). With the best catalytic combination in hand, we next examined various common solvents in lab like tetrahydrofuran, ethyl acetate, and 1,4-dioxane, in which, both reactivities and stereoselectivities decreased of varying degrees (Table 1, entries 10-12). It seems that bases did not affect stereoselectivity control at all, but compared with $\mathrm{KO}^{t} \mathrm{Bu}$ or DIPEA (Table 1, entry 14), inorganic base $\mathrm{K}_{2} \mathrm{CO}_{3}$ lead to poor yield (42\%) which may due to the poor solubility of $\mathrm{K}_{2} \mathrm{CO}_{3}$ in toluene (Table 1, entry 13). Through the experiments above, we finally confirmed the optimal reaction conditions: $5 \mathrm{~mol} \%$ of $\mathrm{Cu}\left(\mathrm{CH}_{3} \mathrm{CN}\right)_{4} \mathrm{PF}_{6}, 6$ mol\% of $(S)$-DTBM-segphos, $20 \mathrm{~mol} \%$ of $\mathrm{KO}^{t} \mathrm{Bu}, 2 \mathrm{~mL}$ of toluene, under $80^{\circ} \mathrm{C}$

Substrate scope of azomethine ylides and $\mathrm{gem}$-difluoroalkenes. Then we investigated the reaction of various substituted imino esters 1 with 2a under optimal conditions, and results are summa- 


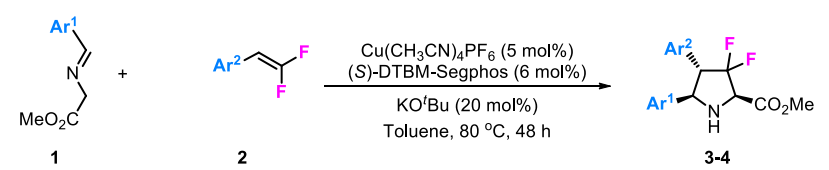

Substrate scope of imino esters

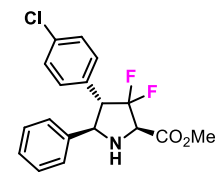

3a, $91 \%$

$3 \mathrm{a}, 91 \%$
20:1 dr, $95 \%$ ee

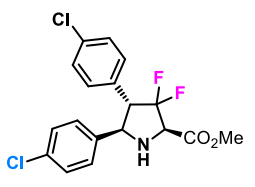

$3 \mathbf{g}, 81 \%$

$>20: 1 \mathrm{dr}, 96 \%$ ee

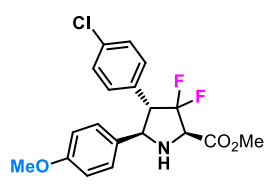

$3 \mathrm{~m}, 80 \%$
$>20: 1 \mathrm{dr}, 94 \%$ ee

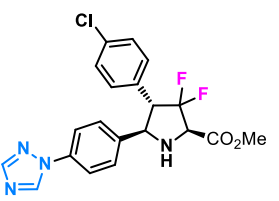

$3 \mathbf{s}, 87 \%$
$>20: 1 \mathrm{dr}, 97 \%$ ee

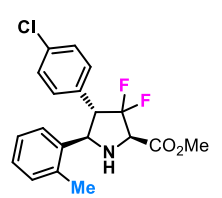

3b, $66 \%$ $>20: 1 \mathrm{dr}, 97 \%$ ee

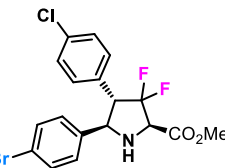

3h, $79 \%$

$>20: 1 \mathrm{dr}, 97 \%$ ee

cI

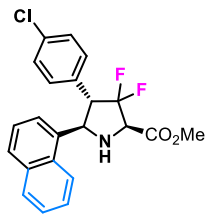

$3 n, 83 \%$

$>20: 1 \mathrm{dr}, 89 \%$ e

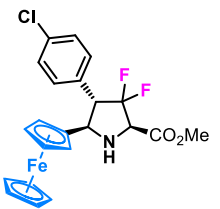

3t, $68 \%$
$>20: 1 \mathrm{dr}, 79 \%$ ee

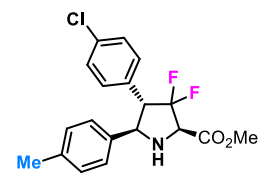

$3 c, 95 \%$
$>20: 1 \mathrm{dr}, 94 \%$ ee

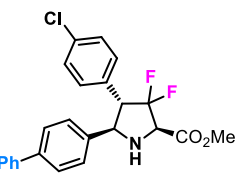

$3 i, 74 \%$

$>20: 1 \mathrm{dr}, 86 \%$ ee

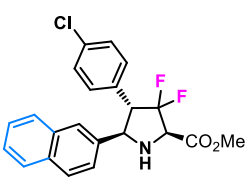

3o, $97 \%$

$>20: 1 \mathrm{dr}, 87 \%$ ee

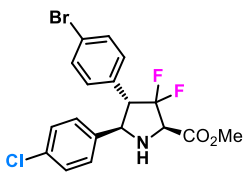

$3 u, 79 \%$
$>20: 1 \mathrm{dr}, 91 \%$ ee

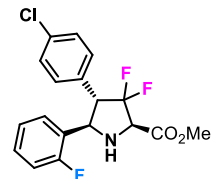

3d, $88 \%$

$>20: 1 \mathrm{dr}, 97 \%$ ee

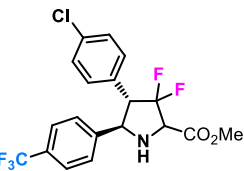

$3 \mathbf{j}, 96 \%$
$>20: 1 \mathrm{dr}, 97 \%$

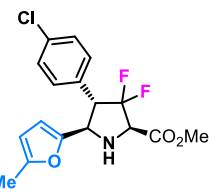

$3 p, 54 \%$
$20: 1 \mathrm{dr}, 71 \%$

$>20: 1 \mathrm{dr}, 71 \%$ ee

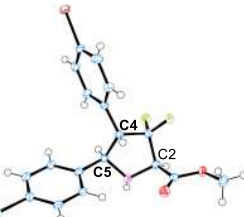

$\mathrm{X}$-ray of $(2 R, 4 S, 5 R)-3 \mathrm{u}$

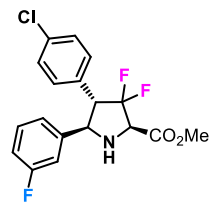

3 e, $60 \%$

$>20: 1 \mathrm{dr}, 90 \%$ ee

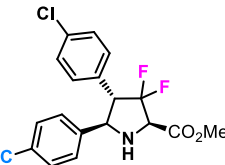

$3 \mathbf{k}, 78 \%$

$>20: 1 \mathrm{dr}, 85 \%$ ee

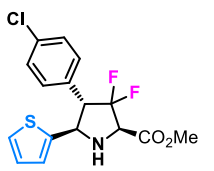

3q, $85 \%$ $>20: 1 \mathrm{dr}, 83 \%$ ee

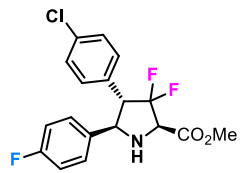

3f, $71 \%$

$>20: 1 \mathrm{dr}, 94 \%$ ee

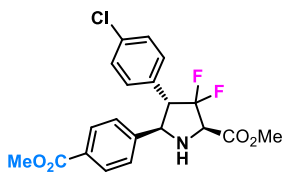

$31,81 \%$

$>20: 1 \mathrm{dr}, 94 \%$ ee

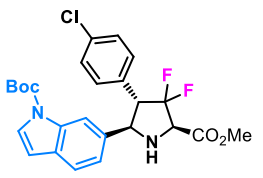

$3 r, 56 \%$ $>20: 1 \mathrm{dr}, 90 \%$ e

Substrate scope of gem-difluoroalkenes

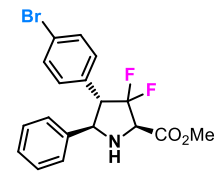

$4 a, 85 \%$

$>20: 1 \mathrm{dr}, 90 \%$ ee
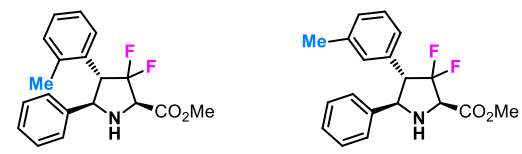

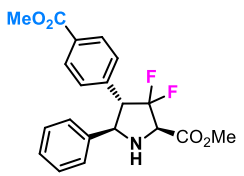

$4 c, 96 \%$

$>20: 1 \mathrm{dr}, 97 \%$ ee

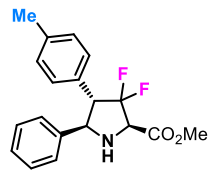

$4 \mathrm{i}, 57 \%$
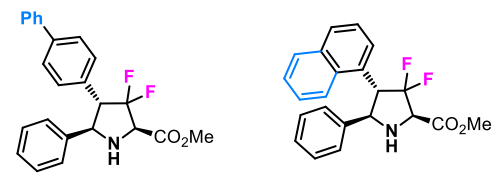

$4 d, 76 \%$
$>20: 1 \mathrm{dr}, 86 \%$ ee

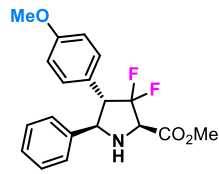

$>20: 1 \mathrm{dr}, 95 \%$ ee

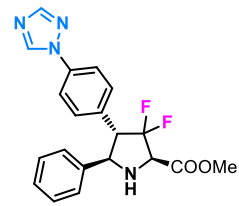

$4 \mathrm{j}, 75 \%$ $\mathbf{4 k}, 91 \%$
$>20: 1 \mathrm{dr}, 81 \%$ ee

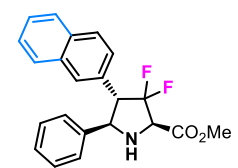

4f, $72 \%$ $>20: 1 \mathrm{dr}, 94 \%$ ee

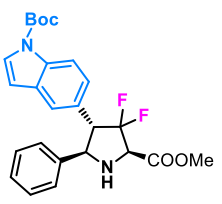

$4 \mathbf{l}, 79 \%$ > 20:1 dr, $92 \%$

${ }^{a}$ All reactions were carried out with $0.40 \mathrm{mmol}$ of $\mathbf{1}$ and $0.20 \mathrm{mmol}$ of $\mathbf{2}$ in $2 \mathrm{~mL}$ toluene. Isolated yield, $\mathrm{dr}$ was determined by crude ${ }^{1} \mathrm{H}$ NMR and ee was determined by chiral HPLC.

rized in Table 2. Besides product 3a, various substituted chiral difluoropyrrolidines can be prepared as one single diastereomer by this method. Steric effect of substituents did not influence the stereoselectivies, ortho- and para-Me substituted products $\mathbf{3 b} \mathbf{3}-\mathbf{3 c}$ were obtained with excellent enantioselectivities (97\%, 94\% ee respectively), while reactivities were affected a lot, ortho-Me imino ester gave product $\mathbf{3 b}$ only in $66 \%$ yield, while para-Me substituted substrate gave $95 \%$ yield. Fluoro-substituted products 3d-3f were obtained with similar results, except meta-fluoro-product 3e (60\%).
Other halogen substituents like chloride or bromide also tolerant this reaction condition, providing corresponding products $\mathbf{3 g}$ and 3h in good yields $(81 \%, 79 \%)$ and high enantioselectivities $(96 \%$, $97 \%$ ee). Biphenyl group containing derivative $\mathbf{3 i}$ was created in $74 \%$ yieldand with high enantioselectivity ( $86 \%$ ee). As shown in Table 2, substrates bearing strong electron withdrawing substituents like $-\mathrm{CF}_{3},-\mathrm{CN}$, and $-\mathrm{CO}_{2} \mathrm{Me}$ performed very well in this reaction, leading to the desired products $\mathbf{3 j}$-3l with good reactivities (78-96\% yields) and stereoselectivities (> 20:1 dr, 85- 


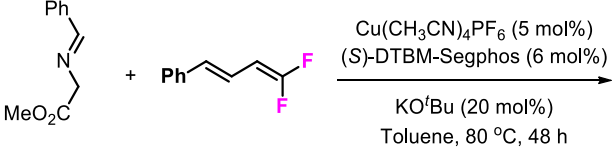

$1 \mathrm{a}$

$2 m$

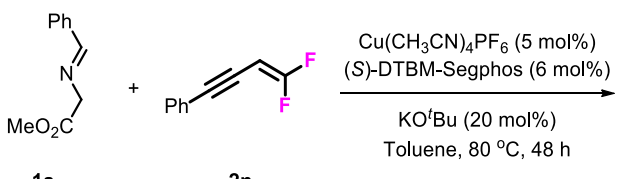

2n

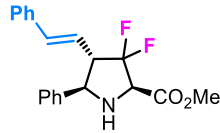

$4 \mathrm{~m}, 53 \%$ $>20: 1 \mathrm{dr}, 88 \%$ ee $\mathrm{Ph}$

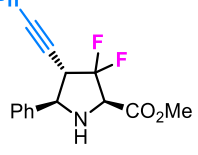

$4 n, 51 \%$

$>20: 1 \mathrm{dr}, 84 \%$ ee

Scheme 2 | Reactions of gem-difluorodiene and gem-difluoroenyne.

97\% ee). While strong electron donating group -OMe showed no influence on this reaction (3m). Both 1-Naphthyl and 2-Naphthyl substituted difluoropyrrolidines 3n and 3o were readily prepared with satisfied results. Considering the important role of heterocycle units in biologically active compounds, we in-vestigated four substrates containing furyl, theinyl, indolyl and triazolyl in this transformation to our delight, all of the corresponding products $\mathbf{3 p}$, 3q, $3 \mathbf{r}$ and $3 \mathbf{s}$ were obtained in moderate to good yields (54-87\%) and enantioselectivies (71-97\% ee). We also tried an imino ester bearing ferrocene group (3t). The reaction worked although with moderate yield (68\%) and enantioselectivity (79\% ee). Finally, the absolute configuration of $3 \mathrm{u}$ was determined to be $(2 R, 4 S, 5 R)$ by $\mathrm{X}$-ray analysis. Encouraged by the cheering results of imino esters,

we next examined a series of substituted gem-difluoroalkenes. As mentioned before, normal aromatic alkenes could not be used in 1,3-dipolar cycloaddition of azomethine ylide, except that activated by strong electron withdrawing substituents on phenyl rings, however, due to the electron withdrawing inductive effect of fluorine atom, all substrates with electron rich, neutral and deficient substituents can be used in this reaction. Results are summarized in Table 2, product $\mathbf{4 a}$ with bromide substituent was prepared with similar result to $3 \mathbf{a}$ ( $85 \%$ yield, > 20:1 dr, $90 \%$ ee).

As excepted, substrates with electron withdrawing groups such as $-\mathrm{CF}_{3}$ and $-\mathrm{CO}_{2} \mathrm{Me}$ performed very well in this reaction and provided corresponding products $\mathbf{4 b}$ and $\mathbf{4 c}$ in high yields $(94 \%, 96 \%)$ and excellent enantioselectivities (95\%, 97\% ee). Diphenyl alkene can be used in this transformation although the enantioselectivity is somewhat lower ( $86 \%$ ee). It seems that steric effect does not affect stereoselective control in this reaction, for example, 1-Naphthyl and 2-Napthyl substituted gemdifluoroalkenes showed similar results $(81 \%, 95 \%$ ee and $72 \%$, $94 \%$ ee respectively). Meanwhile, ortho-, meta- and para-methyl substituted products $\mathbf{4 g}-\mathbf{4 i}$ could be created by this method with same enantioselectivies $(94 \%, 94 \%, 92 \%$ ee) while in different yields $(59 \%, 74 \%, 57 \%)$. Substrate with strong electron donating group -OMe went smoothly and gave product $\mathbf{4} \mathbf{j}$ with $>20: 1 \mathrm{dr}$ and $94 \%$ ee despite of moderate yield (75\%). Meanwhile, we synthesized two gem-difluoroalkenes bearing 1-triazolyl and 6indolyl substituents and texted their applicability in this

Table 3 | Modification of natural compounds and pharmaceuticals. ${ }^{a}$

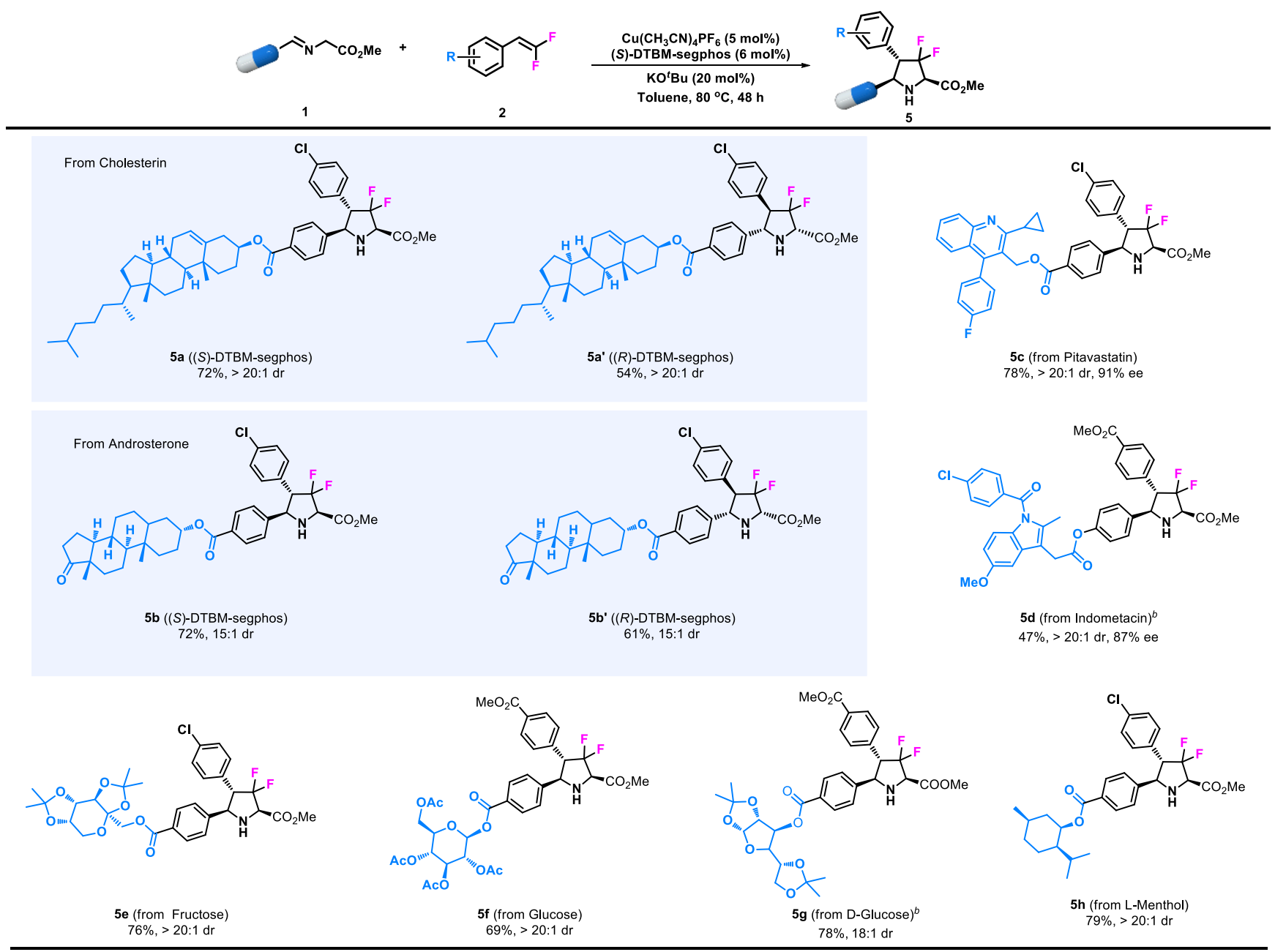

${ }^{a}$ All reactions were carried out with $0.40 \mathrm{mmol}$ of 1 and $0.20 \mathrm{mmol}$ of 2 in $2 \mathrm{~mL}$ toluene. ${ }^{b}$ The reactions were carried out at $60{ }^{\circ} \mathrm{C}$ for $96 \mathrm{~h}$. 

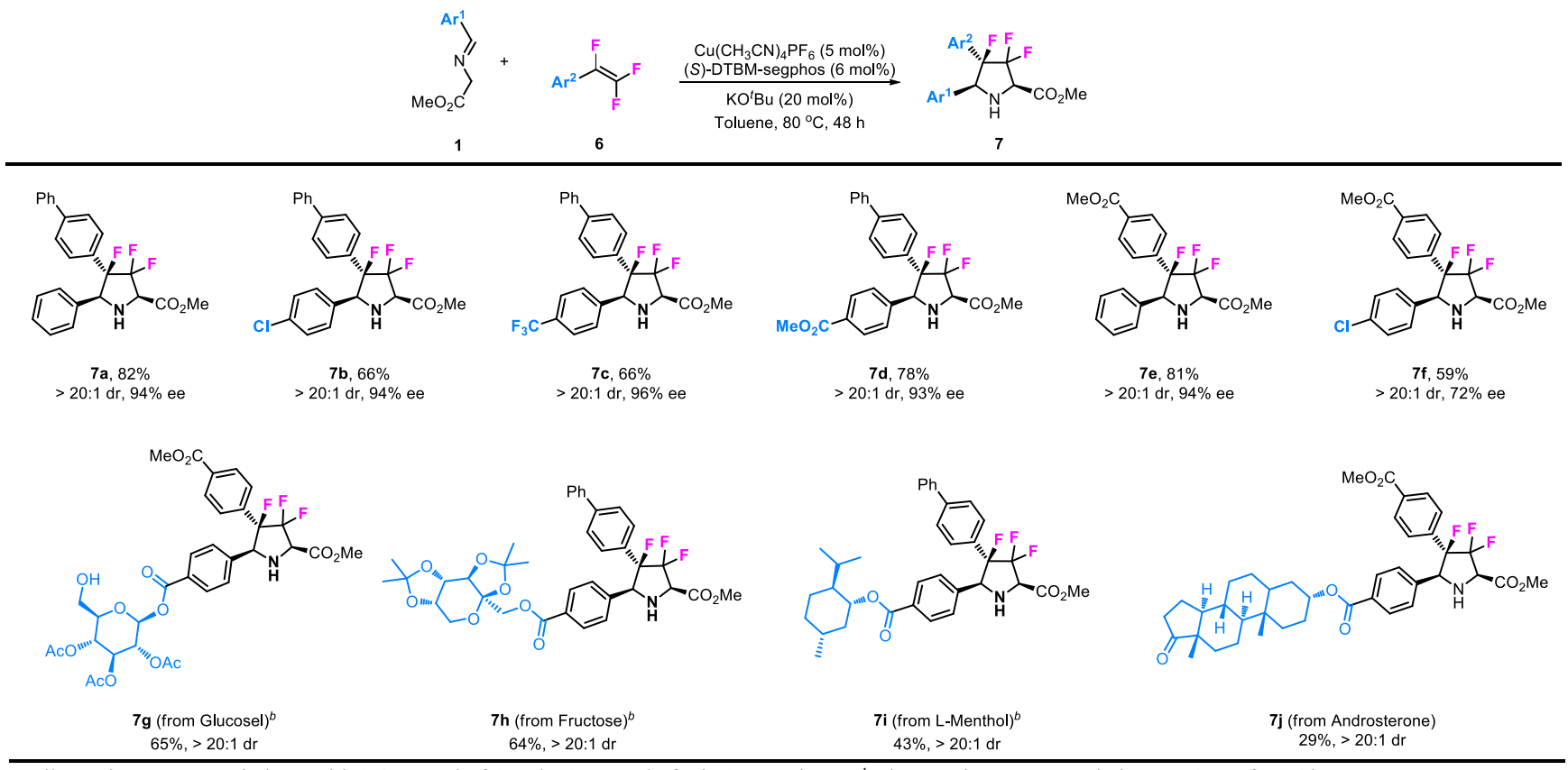

${ }^{a}$ All reactions were carried out with $0.40 \mathrm{mmol}$ of 1 and $0.20 \mathrm{mmol}$ of 6 in $2 \mathrm{~mL}$ toluene. ${ }^{b}$ The reactions were carried out at $60{ }^{\circ} \mathrm{C}$ for $96 \mathrm{~h}$.

transformation, to our delight, the desired products $\mathbf{4 k}$ and $\mathbf{4 l}$ were prepared with satisfied results.

Gem-difluorodiene $\mathbf{2 m}$ derived from cinnamaldehyde also participated in this reaction, giving product $\mathbf{4 m}$ bearing styryl group at 4-position with $>20: 1 \mathrm{dr}$ and $88 \%$ ee althoughin oderate yield $(53 \%)$. Similar result also obtained with gem-difluoroenyne 2n as fluorinating precursor to access the corresponding product $4 \mathbf{n}$ with an alkynyl group. (Scheme 2)

Modification of natural compounds and drugs. Additionally, since the modification of biologically active compounds is an important method for the development of agrochemicals and pharmaceuticals, the introduction of certain units into biologically active molecules is of great significance. Therefore, we further demonstrate the broad applicability of the asymmetric transformation protocol by examination of imino esters derived from natural compounds and currently existed synthetic drugs. As shown in Table 3, the desired product 5a bearing cholesterin unit could be readily prepared in $72 \%$ yield and with $>20: 1 \mathrm{dr}$ under the optimized reaction conditions, similarly, androsterone derived imino ester could participate in this reaction to access adduct $\mathbf{5} \mathbf{b}$, notably, their diastereomers $\mathbf{5} \mathbf{a}^{\prime}$ and $\mathbf{5} \mathbf{b}^{\prime}$ could also be prepared in high yield and stereoselectivity by using $\mathrm{Cu}(\mathrm{I}) /(R)$-DTBM-segphos as catalyst. Pitavastatin, which is an important building skeleton in drugs, could also be employed in this reaction to give $\mathbf{5 c}$ in good yield (78\%) and with excellent stereoselectivity (> 20:1 dr and 91\% ee). Meanwhile, the well-known commercial analgesic indomethacin has been modified by this method, leading to the corresponding derivative $\mathbf{5 d}$ in moderate yield (47\%) together with excellent stereoselectivity ( $>20: 1 \mathrm{dr}$ and $87 \%$ ee). Encouraged by these results, we next texted saccharide derivatives which are important components in medicines while contain multiple sensitive functional groups. The asymmetric cycloaddition of imino esters derived from fructose and glucose were readily achieved, leading to the corresponding products $5 \mathbf{e}-\mathbf{5 g}$ respectively in high yields (69-78\%) and stereoselectivities (18:1 - >20:1 dr). Finally, L-menthol is no doubt one of the most important chiral precursors for the synthesis of agrochemicals and pharmaceuticals, in this work, we combined this unit with difluoro-pyrrolidinyl motif easily to give product $\mathbf{5 h}$ in $79 \%$ yield and $>20: 1 \mathrm{dr}$.
1,3-Dipolar cycloaddition of 1,1,2-trifluoroalkenes. Besides 3,3difluoropyrrolidines, chiral 3,3,4-trifluoropyrrolidinyl derivatives were also prepared by using 1,1,2-trifluoroalkenes as substrates in this transformation. As shown in table 4, various substituted 1,1,2trifluorostyrenes could readily participate in this reaction to access corresponding chiral 3,3,4-trifluoro pyrrolidine derivatives. All simply structured imino esters and trifluoroalkenes can be applied as compatible reactants, leading to desired 3,3,4-trifluoropyrrolidines 7a-7f in moderate to good yields (59-82\%) and with excellent stereoselectivities (> 20:1 dr and 72-96\% ee). Meanwhile, similar to the synthesis of 3,3-difluoropyrrolidines, we introduced these unique structural motifs into some kinds of biologically active natural compounds such as glucose $\mathbf{( 7 g})$, fructose $(\mathbf{7 h})$, L-menthol (7i) and androsterone (7j), it needs to be mentioned that these reactions should be conducted at $60{ }^{\circ} \mathrm{C}$ to prevent decomposition of the obtained products.

Scale-up reactions. To test the practicability of this methodology, gram-scale synthesis of $\mathbf{3 u}$ and $\mathbf{7 b}$ were examined under the optical conditions (Scheme 3 ). The reaction of $7.5 \mathrm{mmol}$ of imino ester $\mathbf{1 g}$ with $5 \mathrm{mmol}$ of $\mathrm{gem}$-difluoroalkene $\mathbf{2 b}$ performed very well and gave $1.66 \mathrm{~g}$ of product $3 \mathbf{u}$ in $77 \%$ yield, and with high stereoselectivity (> 20:1 dr and $91 \%$ ee), while $1.45 \mathrm{~g}$ of 3,3,4trifluoro pyrrolidine $\mathbf{7 b}$ can be prepared by the reaction of $7.5 \mathrm{mmol}$ of imino ester $\mathbf{1 g}$ with $5 \mathrm{mmol}$ of 1,1,2-trifluoroalkene $\mathbf{6 a}$.

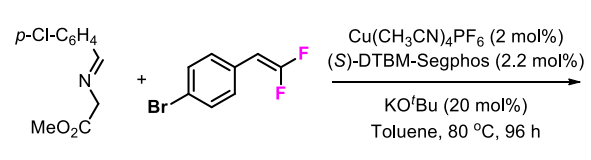

$1 \mathrm{~g}(7.5 \mathrm{mmol}) \quad 2 \mathrm{~b}(5 \mathrm{mmol})$
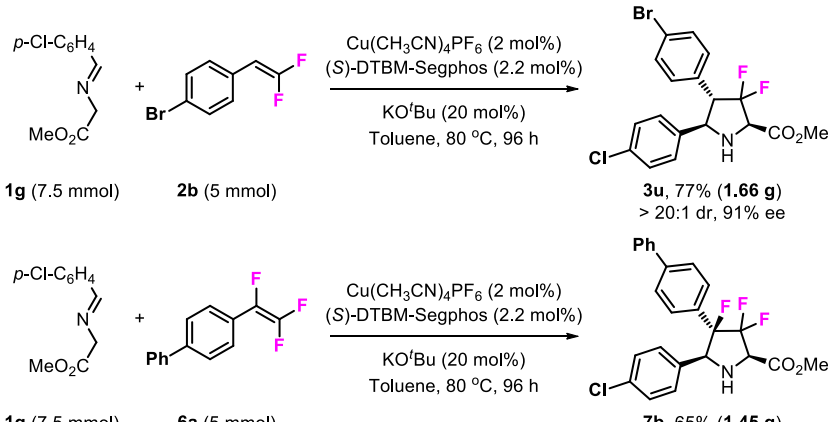

$3 \mathrm{u}, 77 \%(1.66 \mathrm{~g})$ $>20: 1 \mathrm{dr}, 91 \% \mathrm{ee}$

$(7.5 \mathrm{mmol})$

$6 a(5 \mathrm{mmol})$

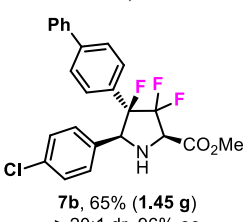

$>2 b, 65 \%(1.45 \mathrm{~g})$

Scheme 3 | Gram-scale reactions. 

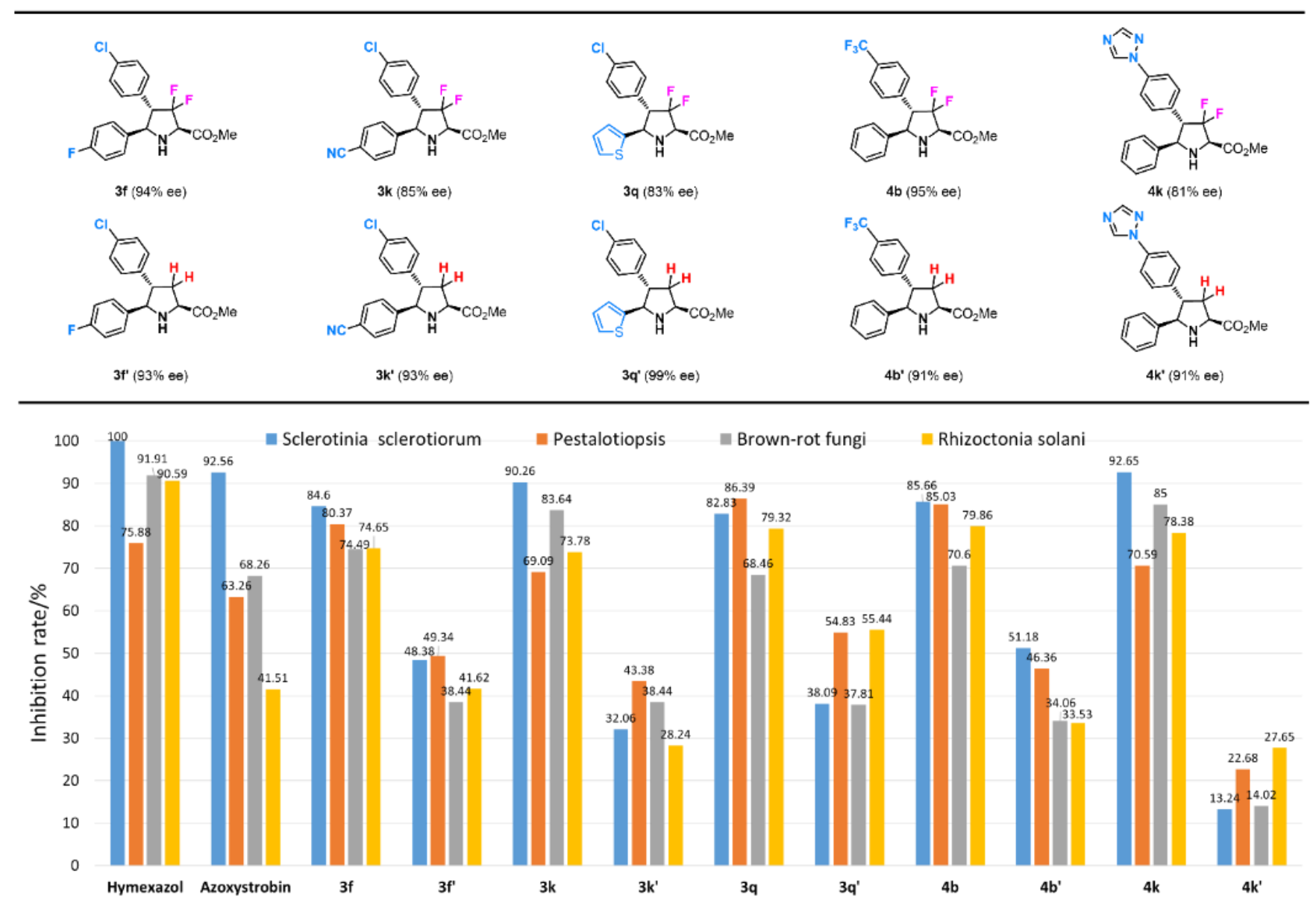

Antifungal activities evalution. With these unique fluorinated compounds in hands, we next texted their antifungal activities. In this part, four common funguses Sclerotinia sclerotiorum, Pestalotiopsis, Brown-rot fungi and Rhizoctonia solani as experimentally inhibitory subjects. Meanwhile, two popular and commercial antifungal insecticides hymexazol, azoxystrobin as contraposition. As shown in Table S1, most 3,3-difluorinated products showed general antifungal activities against four funguses, however, in contrast, most 3,3,4-trifluoro-compounds gave poorer results. Among all biologically active difluoropyrrolidines, products 3f, 3k, 3q, 4b, 4k provided similar and even better antifungal inhibition effects in compare with hymexazol and azoxystrobin (Table 5). It seems that additional fluorine groups contribute a lot to the antifungal inhibition. Product $3 \mathbf{f}$ with an additional fluorine atom at the para-position of phenyl group gave $84.60 \%, 80.37 \%, 74.49 \%, 74.65 \%$ inhibition rate against Sclerotinia sclerotiorum, Pestalotiopsis, Brown-rot fungi and Rhizoctonia solani respectively, and similarly, compound $\mathbf{4 b}$ which has a trifluoromethyl $\left(\mathrm{CF}_{3}\right)$ substituent also showed great results $(85.66 \%, 85.03 \%, 70.62 \%, 79.86 \%)$. Meanwhile, product $3 \mathbf{k}$ bearing a cyano-group $(\mathrm{CN})$ also performed very well towards all funguses $(90.26 \%, 69.09 \%, 83.64 \%, 73.78 \%)$. Heterocycles, which are important building blocks in agricultural compounds, often provided key contribution to the bioactivity, for example, thienyl substituted product $\mathbf{3 q}$ can inhibit these funguses effectively $(82.83 \%, 86.39 \%, 68.46 \%, 79.32 \%)$, and the same results were obtained by compound $4 \mathbf{k}$ with 1,2,4-triazolyl unit $(92.65 \%$, $70.59 \%, 85.05 \%, 78.38 \%$ ). These experimental results reveal that the combination of certain functional groups is necessary to enhance the biologically activities.

As mentioned in the beginning, fluorine factors plays an crucial role in biological activity, therefore, in order to confirm the contribution of fluorine atoms in these structures on the antifungal inhibitory reactivity, a series of corresponding chiral pyrrolidinyl derivatives $\mathbf{3} \mathbf{f}^{\prime}, \mathbf{3} \mathbf{k}^{\prime}, \mathbf{3} \mathbf{q}^{\prime}$, $\mathbf{4} \mathbf{b}^{\prime}$, $\mathbf{4} \mathbf{k}^{\prime}$ without fluorine atoms at the heterocyclic rings were readily prepared according to $\mathrm{J}$. C. Carretero's methods. ${ }^{55}$ Antifungal inhibition results of these contrapositive compounds were summarized in Table 5 and Table $\mathrm{S} 2$, the antifungal activities between fluorinated compounds and their contrasts are quite different, as excepted, all the contrapositive samples gave poor results in antifungal experiments. 3f' showed only about half of the inhibition rate of $\mathbf{3 f}$ against Sclerotinia sclerotiorum, Pestalotiopsis and Brown-rot fungi, Rhizoctonia solani $(48.38 \%, 49.34 \%, 38.44 \%, 41.62 \%$ respectively). 3k' and $\mathbf{3 q}$ ' lead to even lower biological reactivities $(32.06 \%, 43.38 \%$, $38.44 \%, 28.24 \%$ and $38.09 \%, 54.83 \%, 37.81 \%, 55.44 \%$ ). Compound $\mathbf{4} \mathbf{b}^{\prime}$ bearing a trifluoromethyl $\left(\mathrm{CF}_{3}\right)$ group also provided moderate inhibition rate towards the four funguses $(51.18 \%$, $46.36 \%, 34.06 \%, 33.53 \%)$. Furthermore, the none-fluorinated trizolyl-substituted contrast $\mathbf{4} \mathbf{k}^{\mathbf{\prime}}$ showed almost no effect on the antifungal inhibition $(13.24 \%, 22.68 \%, 14.02 \%, 27.65 \%)$. Through these control experiments, we can see that the two fluorine atoms at the pyrrolidine ring play a crucial role in their biological activities.

Meanwhile, antifungal experiments of racmic samples were carried out under same conditions, as shown in Table S2, ( \pm -3f, 
Table 6 | Inhibitory effect on Sclerotinia sclerotiorum plant pathogenic fungi under different concentration.

\begin{tabular}{cccccc}
\hline $\mathrm{C} / \mathrm{mg} \cdot \mathrm{L}^{-1}$ & $\mathbf{6 . 2 5}$ & $\mathbf{1 2 . 5 0}$ & $\mathbf{2 5 . 0 0}$ & $\mathbf{5 0 . 0 0}$ & $\mathbf{1 0 0 . 0 0}$ \\
\hline $\mathbf{3 f}$ & 40.00 & 44.56 & 64.41 & 83.24 & 84.60 \\
$\mathbf{3 k}$ & 38.53 & 50.15 & 69.26 & 78.82 & 90.26 \\
$\mathbf{3 q}$ & 0.00 & 28.68 & 62.35 & 71.62 & 82.83 \\
$\mathbf{4 b}$ & 56.00 & 63.97 & 81.47 & 82.50 & 85.66 \\
$\mathbf{4 k}$ & 0.00 & 13.18 & 47.95 & 70.62 & 92.65 \\
Hymexazol & 59.33 & 59.18 & 65.14 & 83.61 & 100.00 \\
Azoxystrobin & 45.32 & 55.30 & 92.55 & 95.38 & 92.56 \\
\hline
\end{tabular}

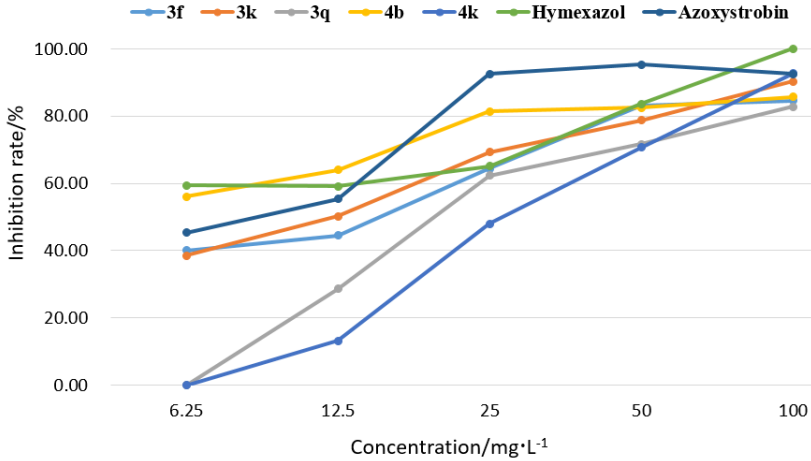

$( \pm)$-3q and ( \pm )-4b gave slight poor results compare with chiral samples, but $( \pm)-\mathbf{3 k}$ and $( \pm)-\mathbf{4 k}$ showed very poor antifungal inhibition. This revealed that stereoselectivity is also a key factor on biologically activity.

Considering the requirement for low pesticide dosage in modern practical application, we finally examined the antifungal inhibition effects of these active compounds under different concentrations $\left(6.25,12.50,25.00,50.00,100.00 \mathrm{mg} \cdot \mathrm{L}^{-1}\right)$ with Sclerotinia sclerotiorum as research subject. As shown in Scheme 4, all inhibition rates decreased as the concentration reduced from 100.00 to $6.25 \mathrm{mg} \cdot \mathrm{L}^{-1}$, but their rates of decline are different. The inhibition effects of $\mathbf{3 q}$ and $\mathbf{4 k}$ drop sharply and no effects was observed with $6.25 \mathrm{mg} \cdot \mathrm{L}^{-1}$ concentration, while that of $\mathbf{3 f}$ and $\mathbf{3 k}$ declined slower and still possess similar inhibition rates with commercial pesticides Hymexazol and Azoxystrobin at $6.25 \mathrm{mg} \cdot \mathrm{L}$ 1. The best result was obtained by $\mathbf{4 b}$, whose antifungal effect maintained at the same level from 100.00 to $25.00 \mathrm{mg} \cdot \mathrm{L}^{-1}$, and gave $56 \%$ inhibition rate even with $6.25 \mathrm{mg} \cdot \mathrm{L}^{-1}$ concentration. This result illustrate that this structure has some kind of potential application in agricultural compound creation.

\section{Conclusion}

In conclusion, we achieved an asymmetric 1,3-dipolar cycloaddition of azomethine ylides with less active 1,1-gemdifluoroalkenes and 1,1,2-trifluoroalkenes, leading to a series of novel chiral 3,3-difluoro- and 3,3,4-trifluoropyrrolidinyl derivatives. This methodology features with high yields (up to $96 \%$ yield), stereoselectivity (up to $>20: 1 \mathrm{dr}$ and $97 \%$ ee) and broad substrate scope (55 cases). Biological activity of these newly prepared compounds has been evaluated via antifungal experiments, some of these fluorinated pyrrolidines performed very well in antifungal experiments against Sclerotinia sclerotiorum, Pestalotiopsis, Brown-rot fungi and Rhizoctonia solani. Control experiments proved that the fluorine atoms on heterocyclic rings are crucial to the biological activity. This work not only developed a facile route for the synthesis of novel biologically active fluorinated pyrrolidinyl derivatives, but also provide a direct evidence for the impact of fluorine atom on the antifungal activity. We believe this research work will give some elicitation for bioactive molecules creation.

\section{Experimental section}

General procedure for the synthesis of 3,3-difluoro-and 3,3,4trifluoropyrrolidines. Under $\mathrm{N}_{2}$ atmosphere, $\mathrm{Cu}\left(\mathrm{CH}_{3} \mathrm{CN}\right)_{4} \mathrm{PF}_{6}$ $(3.7 \mathrm{mg}, 0.01 \mathrm{mmol})$ and $(S)$-DTBM-segphos (14.2 $\mathrm{mg}, 0.012$ $\mathrm{mmol}$ ) were dissolved in $2.0 \mathrm{~mL}$ of toluene and stirred at room temperature for $1 \mathrm{~h}$. Then, $\mathrm{KO}^{t} \mathrm{Bu}(0.04 \mathrm{mmol}, 0.2 \mathrm{eq}$. $)$, imino esters 1 ( $0.4 \mathrm{mmol}, 2.0$ eq.), 1,1-gem-difluoroalkenes 2 or 1,1,2trifluoroalkenes $\mathbf{6}(0.2 \mathrm{mmol}, 1.0$ eq. $)$ were added successively, the reaction was kept at $80{ }^{\circ} \mathrm{C}$ for $48 \mathrm{~h}$. After completion determined by TLC, solvent was removed under vacuum and diastereoselectivity was determined by crude ${ }^{1} \mathrm{H}$ NMR, then the reaction mixture was purified by flash chromatography on silica gel to give the corresponding fluorinated pyrrolidines, whose enantiomeric excess was analyzed directly by chiral HPLC.

Methods for antifungal activity investigation. All tested compounds $(10 \mathrm{mg})$ were dissolved in $1.0 \mathrm{~mL}$ acetone, then the solution was added to $100 \mathrm{~mL}$ of Potato Dextrose Agar medium to prepare a drug-loaded PDA medium plate having a concentration of $100 \mathrm{mg} \cdot \mathrm{L}^{-1}$, and $1.0 \mathrm{~mL}$ acetone was added to the PDA as a blank sample. Commercial pesticides azoxystrobin and hymexazol were chose as compared positive fungicides samples. Sclerotinia sclerotiorum, Pestalotiopsis, Brown-rot fungi and Rhizoctonia solani were activated beforehand (prepared by a punch with $\Phi=0.50 \mathrm{~cm}$ ), and then they were cut from the edge of the colony and inoculated into the above PDA plate, each strain and blank control experiment were repeated twice. After sealed with a sealing film to prevent contamination of other bacteria, the poisonous PDA culture dishes were placed in a constant temperature incubator at the temperature condition of $24 \pm 1^{\circ} \mathrm{C}$. After the blank control group culture was grown to about two-thirds of the culture dish, the colony diameter was measured by the cross method in millimeters $(\mathrm{mm})$ with a cross and a vertical method, and the average value was taken, and the inhibition rate of each compound against the fungus was calculated.

\section{References}

1. Harper, D. B.; O'Hagan, D. The fluorinated natural products. Nat. Prod. Rep., 11, 123-133 (1994).

2. Hiyama, T. (2000) Organofluorine compounds: chemistry and applications (Springer Science \& Business Media).

3. Hagmann, W. K. The many roles for fluorine in medicinal chemistry. $J$. Med. Chem. 51, 4359-4369. (2008).

4. Kirsch, P. (2013) Modern fluoroorganic chemistry: synthesis, reactivity, applications (John Wiley \& Sons).

5. Jeschke, $\mathrm{P}$. The unique role of fluorine in the design of active ingredients for modern crop protection. Chembiochem, 5, 570-589 (2004).

6. Smart, B. E. Fluorine substituent effects (on bioactivity). J. Fluor. Chem., 109, 3-11 (2001).

7. Chambers, R. D. (2004) Fluorine in organic chemistry (CRC press).

8. Soloshonok, V. A. (2005) Fluorine-containing synthons (ACS Publications)

9. Uneyama, K. (2008) Organofluorine chemistry (John wiley \& sons).

10. Bégué, J.-P.; Bonnet-Delpon, D. (2008) Bioorganic and medicinal chemistry of fluorine (John Wiley \& Sons).

11. Ametamey, S. M.; Honer, M.; Schubiger, P. A. Molecular imaging with PET. Chem. Rev., 108, 1501-1516 (2008).

12. Tressaud, A.; Haufe, G. (2008) Fluorine and health: molecular imaging, biomedical materials and pharmaceuticals (Elsevier).

13. O'Hagan, D.; Deng, H. Enzymatic fluorination and biotechnological developments of the fluorinase. Chem. Rev., 115, 634-649 (2015).

14. Sicard, A. J.; Baker, R. T. Fluorocarbon refrigerants and their syntheses: past to present. Chem. Rev., 120, 9164-9303 (2020).

15. McGrath, N. A.; Brichacek, M.; Njardarson, J. T. A graphical journey of innovative organic architectures that have improved our lives. J. Chem. Educ., 87, 1348-1349 (2010)

16. Zhu, W.; Wang, J.; Wang, S.; Gu, Z.; Aceña, J. L.; Izawa, K.; Liu, H.; Soloshonok, V. A. Recent advances in the trifluoromethylation methodology and new $\mathrm{CF}_{3}$-containing drugs. J. Fluor. Chem., 167, 37-54 (2014).

17. Zhou, Y.; Wang, J.; Gu, Z.; Wang, S.; Zhu, W.; Aceña, J. L.; Soloshonok, V. A.; Izawa, K.; Liu, H. Next generation of fluorine- 
containing pharmaceuticals, compounds currently in phase II-III clinical trials of major pharmaceutical companies: new structural trends and therapeutic areas. Chem. Rev., 116, $422-518$ (2016).

18. Liu, X.; Xu, C.; Wang, M.; Liu, Q. Trifluoromethyltrimethylsilane: nucleophilic trifluoromethylation and beyond. Chem. Rev., 115, 683-730 (2015).

19. Charpentier, J.; Fruh, N.; Togni, A. Electrophilic trifluoromethylation by use of hypervalent iodine reagents. Chem. Rev., 115, 650-682. (2015).

20. Champagne, P. A.; Desroches, J.; Hamel, J.-D.; Vandamme, M.; Paquin, J. -F. Monofluorination of organic compounds: 10 Years of Innovation. Chem. Rev., 115, 9073-9174 (2015).

21. Koike, T.; Akita, M. New horizons of photocatalytic fluoromethylative difunctionalization of alkenes. Chem., 4, 409-437 (2018).

22. Khake, S. M.; Chatani, N. Nickel-catalyzed C-H functionalization using a non-directed strategy. Chem., 6, 1056-1081 (2020).

23. Ding, K.; Lu, Y.; Nikolovska-Coleska, Z.; Qiu, S.; Ding, Y.; Gao, W.; Stuckey, J.; Krajewski, K.; Roller, P. P.; Tomita, Y.; Parrish, D. A.; Deschamps, J. R.; Wang, S. Structure-based design of potent non-peptide MDM2 inhibitors. J. Am. Chem. Soc., 127, 10130-10131 (2005).

24. Michael, J. P. Indolizidine and quinolizidine alkaloids. Nat. Prod. Rep., 25, 139-165 (2008).

25. Roughley, S. D.; Jordan, A. M. The medicinal chemist's toolbox: an analysis of reactions used in the pursuit of drug candidates. J. Med. Chem., 54, 3451-3479 (2011).

26. Kuhnert, M.; Blum, A.; Steuber, H.; Diederich, W. E. Privileged structures meet human T-cell leukemia virus-1 (HTLV1): C2-symmetric 3,4-disubstituted pyrrolidines as nonpeptidic HTLV-1 protease inhibitors. J. Med. Chem., 58, 4845-4850 (2015).

27. Hartung, J.; Greszler, S. N.; Klix, R. C.; Kallemeyn, J. M. Development of an enantioselective [3+2] cycloaddition to synthesize the pyrrolidine core of ABBV-3221 on multikilogram scale. Org. Process Res. Dev., 23, 2532-2537 (2018).

28. Scanio, M. J. C.; Searle, X. B.; Liu, B.; Koenig, J. R.; Altenbach, R.; Gfesser, G. A.; Bogdan, A.; Greszler, S.; Zhao, G.; Singh, A.; Fan, Y.; Swensen, A. M.; Vortherms, T.; Manelli, A.; Balut, C.; Jia, Y.; Gao, W.; Yong, H.; Schrimpf, M.; Tse, C.; Kym, P.; Wang, X. Discovery of ABBV/GLPG-3221, a potent corrector of CFTR for the treatment of cystic fibrosis. ACS Med. Chem. Lett., 10, 1543-1548 (2019).

29. Huisgen, R. 1,3-Dipolar cycloadditions. past and future. Angew. Chem., Int. Ed. Engl., 2, 565-598 (1963).

30. Schreiber, S. L. Target-Oriented and diversity-oriented organic synthesis in drug discovery. Science, 287, 1964-1969 (2000).

31. Padwa, A.; Pearson, W. H. (2002) Synthetic applications of 1,3-dipolar cycloaddition chemistry toward heterocycles and natural products (WileyVCH: New York).

32. Hashimoto, T.; Maruoka, K. Recent advances of catalytic asymmetric 1, 3-dipolar cycloadditions. Chem. Rev., 115, 5366-5412 (2015).

33. Adrio, J.; Carretero, J. C. Stereochemical diversity in pyrrolidine synthesisby catalytic asymmetric 1,3-dipolar cycloaddition of azomethine ylides. Chem.Commun., 55, 11979-11991 (2019).

34. Wei, L.; Chang, X.; Wang, C.-J. Catalytic asymmetric reactions with Nmetallated azomethine ylides. Acc. Chem. Res., 53, 1084-1100 (2020).

35. Zhang, X.; Cao, S. Recent advances in the synthesis and CF functionalization of gem-difluoroalkenes. Tetrahedron Lett., 58, 375-392 (2017).

36. Tian, P.; Feng, C.; Loh, T.-P. Rhodium-catalysed C (sp2)-C (sp2) bond formation via $\mathrm{C}-\mathrm{H} / \mathrm{C}-\mathrm{F}$ activation. Nat. Commun., 6, 1-7 (2015).

37. Xie, J.; Yu, J.; Rudolph, M.; Rominger, F.; Hashmi, A. S. K. Monofluoroalkenylation of dimethylamino compounds through radicalradical cross-coupling. Angew. Chem. Int. Ed., 55, 9416-9421 (2016).

38. Thornbury, R. T.; Toste, F. D. Palladium-catalyzed defluorinative coupling of 1-aryl-2, 2-difluoroalkenes and boronic acids: stereoselective synthesis of monofluorostilbenes. Angew. Chem. Int. Ed., 55, 11629-11632 (2016).

39. Zell, D.; Dhawa, U.; Müller, V.; Bursch, M.; Grimme, S.; Ackermann, L. C-F/C-H functionalization by manganese (I) catalysis: expedient (per) fluoro-allylations and alkenylations. Acs. Catal., 7, 4209-4213 (2017). 40. Lu, X.; Wang, Y.; Zhang, B.; Pi, J.-J.; Wang, X.-X.; Gong, T.-J.; Xiao, B.; Fu, Y. Nickel-catalyzed defluorinative reductive cross-coupling of gemdifluoroalkenes with unactivated secondary and tertiary alkyl halides. J. Am. Chem. Soc., 139, 12632-12637 (2017).

41. Sakaguchi, H.; Uetake, Y.; Ohashi, M.; Niwa, T.; Ogoshi, S.; Hosoya, T. Copper-catalyzed regioselective monodefluoroborylation of polyfluoroalkenes en route to diverse fluoroalkenes. J. Am. Chem. Soc., 139, 12855-12862 (2017).
42. Liu, J.; Yang, J.; Ferretti, F.; Jackstell, R.; Beller, M. Pd-catalyzed selective carbonylation of gem-difluoroalkenes: a practical synthesis of difluoromethylated esters. Angew. Chem. Int. Ed., 58, 4690-4694 (2019). 43. Zhou, L.; Zhu, C.; Bi, P.; Feng, C. Ni-catalyzed migratory fluoroalkenylation of unactivated alkyl bromides with gem-difluoroalkenes. Chem. Sci., 10, 1144-1149 (2019).

44. Li, J.; Liu, M.; Li, Y.; Sun, D.-d.; Shu, Z.; Tan, Q.; Guo, S.; Xie, R.; Gao, L.; Ru, H. Discovery and optimization of non-bile acid FXR agonists as preclinical candidates for the treatment of nonalcoholic steatohepatitis. $J$. Med. Chem., 63, 12748-12772 (2020).

45. Orsi, D. L.; Easley, B. J.; Lick, A. M.; Altman, R. A. Base catalysis enables access to $\alpha$, $\alpha$-difluoroalkylthioethers. Org. Lett., 19, 1570-1573 (2017).

46. Liu, X.; Lin, E. E.; Chen, G.; Li, J.-L.; Liu, P.; Wang, H. Radical hydroboration and hydrosilylation of gem-difluoroalkenes: synthesis of $\alpha$ difluorinated alkylborons and alkylsilanes. Org. Lett., 21, 8454-8458 (2019). 47. Gao, B.; Zhao, Y.; Hu, J. AgF-mediated fluorinative cross-coupling of two olefins: facile access to $\alpha-\mathrm{CF}_{3}$ alkenes and $-\mathrm{CF}_{3}$ ketones. Angew. Chem. Int. Ed., 54, 638-642 (2015).

48. Tian, P.; Wang, C.-Q.; Cai, S.-H.; Song, S.; Ye, L.; Feng, C.; Loh, T.P. F-nucleophilic-addition-induced allylic alkylation. J. Am. Chem. Soc., 138, 15869-15872 (2016).

49. Tang, H. J.; Lin, L. Z.; Feng, C.; Loh, T. P. Palladium-catalyzed fluoroarylation of gem-difluoroalkenes. Angew. Chem. Int. Ed., 56, 98729876 (2017).

50. Daniel, P. E.; Onyeagusi, C. I.; Ribeiro, A. A.; Li, K.; Malcolmson, S. J. Palladium-catalyzed synthesis of $\alpha$-trifluoromethyl benzylic amines via fluoroarylation of gem-difluoro-2-azadienes enabled by phosphinecatalyzed formation of an azaallyl-silver intermediate. ACS Catal., 9, 205 210 (2018).

51. Yoo, W. J.; Kondo, J.; Rodríguez-Santamaría, J. A.; Nguyen, T. V.; Kobayashi, S. Efficient synthesis of -trifluoromethyl carboxylic acids and esters through fluorocarboxylation of gem-difluoroalkenes. Angew. Chem. Int. Ed., 58, 6772-6775 (2019).

52. Liu, H.; Ge, L.; Wang, D. X.; Chen, N.; Feng, C. Photoredox-coupled F-nucleophilic addition: allylation of gem-difluoroalkenes. Angew. Chem. Int. Ed., 58, 3918-3922 (2019).

53. Lin, T. Y.; Pan, Z.; Tu, Y.; Zhu, S.; Wu, H. H.; Liu, Y.; Li, Z.; Zhang, J. Design and synthesis of TY-Phos and application in palladium-catalyzed enantioselective fluoroarylation of gem-difluoroalkenes. Angew. Chem. Int. Ed. 2020, 59, 22957-22982.

54. Filippone, S.; Maroto, E. E.; Martín-Domenech, Á.; Suarez, M.; Martín, N. An efficient approach to chiral fullerene derivatives by catalytic enantioselective 1, 3-dipolar cycloadditions. Nature Chem., 1, 578-582 (2009).

55. Pascual-Escudero, A.; de Cózar, A.; Cossío, F. P.; Adrio, J.; Carretero, J. C. Alkenyl Arenes as Dipolarophiles in Catalytic Asymmetric 1, 3Dipolar Cycloaddition Reactions of Azomethine Ylides. Angew. Chem. Int. Ed., 55, 15334-15338 (2016).

56. Liu, K.; Xiong, Y.; Wang, Z.-F.; Tao, H.-Y.; Wang C.-J. Ligandcontrolled stereodivergent 1,3-dipolar cycloaddition of azomethine ylides with 3-methyl-4-nitro-5-styrylisoxazoles. Chem. Commun., 52, 9458-9461 (2016).

57. Chang, X.; Yang, Y.; Shen, C.; Xue, K.-S.; Wang, Z.-F.; Cong, H.; Tao, H.-Y.; Chung, L. W.; Wang, C.-J. $\beta$ Substituted alkenyl heteroarenes as dipolarophiles in the $\mathrm{Cu}(\mathrm{I})$-catalyzed asymmetric 1,3-dipolar cycloaddition of azomethine ylides empowered by a dual activation strategy: stereoselectivityand mechanistic insight. J. Am. Chem. Soc., 143, 35193535 (2021).

58. McCune, C. D.; Beio, M. L.; Sturdivant, J. M.; de la Salud-Bea, R.; Darnell, B. M.; Berkowitz, D. B. Synthesis and deployment of an elusive fluorovinyl cation equivalent: access to quaternary $\alpha$ (1'-fluoro)vinyl amino acids as potential PLP enzyme inactivators. J. Am. Chem. Soc., 139, 1407714089 (2017).

\section{Supplementary Information}

Available in the online version of the paper, experimental procedures, antifungal experimental results, characterization data, ${ }^{1} \mathrm{H}$ NMR, ${ }^{13} \mathrm{C}$ NMR, and HPLC spectra (PDF).

\section{Acknowledgements}

This work was supported by the National Natural Science Foundation of China (21801086, 22071072) and the Fundamental Research Funds for the Central Universities of China 
(2662018PY052). We thank Prof. Jiasen Cheng and Guotian Li for providing funguses.

\section{Author Contributions}

${ }^{\dagger}$ These authors contributed equally.

X. X. developed the synthetic methods. L. B. performed the antifungal activity investigations. L. R and H. T. participated in the synthetic work. D. Y. took charge in the characterization of compounds. C.-J. W. and H. T. wrote the manuscript with revisions provided by the other authors.

\section{Author Information}

Reprints and permissions information is available at www.nature.com/reprints. The authors declare no competing financial interests. Readers are welcome to comment on the online version of the paper. Correspondence and requests for materials should be addressed to C. -J. W. (cjwang@whu.edu.cn) or H. T. (thlong@mail.hzau.edu.cn) 


\section{Supplementary Files}

This is a list of supplementary files associated with this preprint. Click to download.

- Supportinginformation.pdf 